\title{
Representações dos Educadores Sociais sobre os "Meninos de Rua "
}

\author{
Alda Judith Alves-Mazzotti \\ Universidade Federal do Rio de Janeiro (UFRJ)
}

Procura investigar como os educadores sociais que atuam em programas de atendimento a meninos e meninas de rua no município do Rio de Janeiro representam esta clientela, bem como sua visão sobre aspectos significantes do universo desses meninos e meninas. Adicionalmente, investigou-se como esses educadores situam a questão dos meninos de rua; mais especificamente, a que atribuem a existência do problema, quais as soluções possíveis e qual o papel do educador social no contexto atual. Considerando-se o conjunto das representações apresentadas pelos educadores, identificou-se o seguinte núcleo figurativo: "os meninos de rua são vítimas dos processos de exclusão social a que resistem ". Munidos de coragem, organização social e autonomia, lutam para sobreviver ao complô social que se instalou contra eles, representado pelo modelo socioeconómico iníquo que levou suas famílias à desagregação e à violência; pela escola que os excluiu e pela sociedade que os discrimina.

O reconhecimento de que o direito a uma educação adequada, essencial ao exercício da cidadania, tem sido negado às crianças das chamadas classes populares levou à necessidade de se repensar a escola. Tal reflexão tem enfatizado a importância de se adequar a educação escolar às necessidades, potencialidades e aspirações desse segmento da população, o que vem sendo buscado em diversos projetos pedagógicos. Há, porém, 
outras crianças e adolescentes cuja educação exige projetos bem mais complexos do que os destinados às classes populares. Referimo-nos aos "meninos de rua", isto é, àqueles meninos e meninas que, tendo perdido os vínculos familiares, fazem da ma o seu habitat.

A presença dessas crianças nas mas - pedindo um dinheirinho, arrancando uma bolsa, fazendo um biscate, cheirando cola, dormindo sob uma marquise ou simplesmente vagando sem rumo - as expõe a toda a sorte de riscos, que vão desde a influência negativa de outros indivíduos com quem dividem o espaço social (delinqüentes, traficantes, viciados, prostitutas), até a execução sumária por grupos de extermínio.

Em razão da história de violências sofridas na família e do modo de vida que desenvolvem na ma, essas crianças passam a apresentar características cognitivas, afetivas e comportamentais que restringem seriamente suas possibilidades de adaptação às normas e rotinas da escola regular. Assim, para que possam ser reintegradas à sociedade e, sempre que possível, ao sistema regular de ensino, os meninos e meninas de rua precisam passai- por um estágio de ressocialização que lhes permita fazer essa passagem.

Essas constatações levaram um número crescente de atores sociais a se mobilizarem com o intuito de oferecer alguma forma de ajuda a essas crianças. Valladares e Impelizieri (1991), em minucioso levantamento sobre a ação nãogovernamental voltada para as crianças carentes, localizaram, apenas no Rio de Janeiro, 39 iniciativas, de natureza e filiações diversas, dirigidas exclusivamente a meninos e meninas de rua, incluindo-se aí dez abrigos, 12 projetos de educação alternativa, seis centros de defesa de direitos humanos, oito instituições de articulação e coordenação de projetos, dois projetos de treinamento profissionalizante e uma instituição de assistência social. A quase totalidade dessas instituições e projetos (36) surgiu na década de 80 , em conseqüência da agudização do problema e daí para cá o número de iniciativas, governamentais e nãogovernamentais, dedicadas aos meninos de ma vêm continuando a crescer.

Essas iniciativas procuram, em geral, fugir aos tipos mais tradicionais de atendimento, substituindo internâtes e escolas convencionais por abrigos em regime aberto, propostas de educação alternativa e treinamento profissionalizante. 
A preocupação com os direitos das crianças, despertada principalmente pela mobilização que antecipou a aprovação do Estatuto da Criança e do Adolescente, vem também ganhando espaços antes ocupados por uma visão puramente assistencial. Assim, uma enorme variedade de serviços vem sendo oferecida por essas organizações, incluindo, além de atividades pedagógicas, abrigo e alimentação, ações voltadas para as questões da sexualidade, do consumo de drogas e da auto-organização dos adolescentes, bem como diversas atividades de lazer, desenvolvidas na própria rua ou em outros locais.

Paralelamente às iniciativas de apoio a essas populações, o agravamento do problema levou também a um aumento significativo do número de pesquisas sobre a situação dos meninos e meninas encontrados nas ruas: dos 212 títulos referentes ao assunto, localizados entre 1960 e 1987 por Alvim e Valladares (1988), mais da metade (139) foi publicada entre 80 e 87. E dai para cá, a produção acadêmica sobre a questão só tem crescido. Apesar de realizados em diversas cidades do País, e por diferentes pesquisadores, esses estudos apresentam uma grande consistência entre seus resultados no que se refere ao perfil e ao cotidiano dessas crianças e adolescentes.

Apesar de todos esses esforços, a insuficiência e a irregularidade dos recursos financeiros com que contam as organizações dedicadas aos "meninos de rua" e, sobretudo, a falta de um corpo estável de profissionais qualificados refletem-se na qualidade do atendimento proporcionado, uma vez que a grande maioria dos projetos conta apenas com a boa vontade de pessoas sem qualquer formação específica para a difícil tarefa que se propõem a desempenhar.

A preocupação com essa questão deu origem a uma publicação do Fundo das Nações Unidas para a Infầncia (Unicef), em 1988, sobre o educador de rua, com a finalidade de orientar a reflexão sobre o papel desse profissional. com base nesse documento, Campos e Fávero (1994) definem a educação social de rua como um modelo de intervenção que tem como princípios: a) respeitar o "menino de rua" como sujeito de seu processo educativo e de seu projeto de vida; e b) ter, como ponto de partida do processo educativo, a análise crítica da situação do "menino de rua" e das práticas sociais envolvidas nessa realidade. Segundo esse modelo, o processo educativo deve ter por finalidade desenvolver 
nos meninos e meninas uma consciência crítica sobre sua própria realidade e sobre a sociedade como um todo, levando-os à elaboração de um novo projeto de vida, o que lhe permitirá contribuir para a transformação dessa sociedade.

Esses princípios gerais parecem ser aceitos, pelo menos em tese, pela maioria dos programas dirigidos à ressocialização dos "meninos de rua". Seria ocioso, entretanto, enfatizar as dificuldades inerentes à sua concretização em uma prática, dadas as peculiaridades da história e do modo de vida dos "meninos de rua".

Diante do exposto, é de certa forma surpreendente que cursos para a formação de educadores sociais sejam tão raros. Das instituições citadas por Valladares e Impelizieri (1991), apenas uma - a Fundação São Martinho mantinha um curso de formação de educadores. Quanto às universidades, temos conhecimento de apenas um curso no Estado do Rio de Janeiro, recentemente criado na Universidade Santa Úrsula, para atender a essa necessidade.

É também surprendente que, embora tenham se desenvolvido concomitantemente sob o impacto de um mesmo drama social, programas de atendimento e pesquisas sobre meninos de rua venham trilhando caminhos paralelos, uma vez que aqueles não têm, em geral, se valido dos conhecimentos acumulados por estas. uma avaliação, patrocinada pelo Unicef, focalizando programas alternativos desenvolvidos em diversos estados brasileiros (Penna Firme, Tijiboy, Stone, 1987), evidenciou que estes vinham formulando suas políticas e tomando decisões sobre enfoques e procedimentos guiados exclusivamente por julgamentos subjetivos, sem recurso a dados de pesquisa que pudessem orientar, de maneira mais eficaz, tanto o planejamento quanto a avaliação dos resultados desses programas.

Considerando-se a quantidade de organizações nacionais e internacionais que, desde a década passada, vêm se dedicando ao atendimento dessas crianças e adolescentes, torna-se urgente a formação de educadores qualificados, capazes de lidar de maneira mais integrada com os múltiplos aspectos envolvidos nessa prática educativa. 
Acreditamos que o conhecimento de como os "meninos de rua" são representados pelos educadores sociais pode contribuir para a identificação de aspectos a serem enfatizados, tanto na formação como no treinamento e no aperfeiçoamento em serviço destinados a esses profissionais. Tal afirmação se justifica na medida em que as representações sociais, de um lado, refletem a maneira pela qual definimos aspectos da realidade em relação aos quais nos situamos como atores sociais e, de outro, orientam comunicações e práticas sociais relativas aos objetos representados.

com base nestas considerações, este estudo procurou investigar como educadores sociais que atuam em programas de atendimento de meninos e meninas de rua do município do Rio de Janeiro representam este grupo. Para alcançar esse objetivo, investigamos não apenas como esses educadores caracterizam os "meninos de rua", mas também como se situam diante da questão, ou seja, que papel atribuem ao educador social.

\section{Representação social: conceito e funções}

A noção de representação social aqui utilizada foi introduzida por Moscovici (1978) para referir-se a uma modalidade particular de conhecimento, o saber do senso comum, constituída por um conjunto de informações, crenças, opiniões e atitudes partilhadas por um grupo a respeito de um dado objeto social. Esse conhecimento é gerado coletivamente no contexto das interações sociais cotidianas e tem por função a orientação de condutas e comunicações sociais relativas ao objeto, contribuindo para a formação de "universos consensuais" no âmbito dos grupos e servindo às suas necessidades, valores e interesses.

Diz-se que esse conhecimento é gerado coletivamente porque embora o sujeito desempenhe um papel ativo em sua construção, o mesmo toma por base crenças, modelos de pensamento, valores e elementos simbólicos que circulam, mediante a conversação, no campo social em que ele está inserido. $\mathrm{O}$ fato de que esse conhecimento é partilhado concorre para forjar e consolidar a identidade grupai e o sentimento de pertencimento. 
Em resumo, podemos dizer que as representações sociais constituem uma modalidade de conhecimento cuja especificidade reside no caráter social dos processos que o produzem (Guimelli, 1994), na marca social que esses processos imprimem ao conhecimento produzido e nas funções que desempenha nas interações sociais do sujeito que as constrói.

Assim, ao contrário do que ocorre nos estudos "clássicos" sobre percepções, opiniões ou atitudes, o estudo das representações sociais interessa-se não apenas por um produto, por um pensamento social constituído, mas também pelos processos que lhe deram origem.

No estudo das representações sociais enquanto produto, Moscovici ( 1978) aponta três dimensões que nos permitem apreender seu conteúdo e sentido: a atitude, a informação e o campo de representação ou imagem. A atitude consiste na disposição geral, favorável ou desfavorável, em relação ao objeto da representação, que dinamiza e orienta a conduta diante deste. A informação varia muito em quantidade e qualidade nos diversos grupos e estratos sociais, o que contribui para a diferenciação entre os grupos quanto ao tipo de representação social que se forma. Finalmente, o campo de representação remete à idéia de imagem, ao conteúdo concreto e limitado de elementos referentes a um aspecto preciso do objeto, e pressupõe organização, ordenação e hierarquização desses elementos.

Ao analisar a gênese das representações, Moscovici descreve dois processos dialeticamente relacionados: a objetivação e a ancoragem. A objetivação consiste na transformação de um conceito ou de uma idéia em algo concreto. Nesse processo, as informações que circulam sobre o objeto sofrem uma triagem, em função de condicionantes culturais (acesso diferenciado às informações em decorrência da inserção grupai do sujeito) e, sobretudo, de critérios normativos (só se retendo aquilo que está de acordo com o sistema de valores circundante), de modo a proporcionar uma imagem coerente e facilmente exprimível dos elementos que constituem o objeto da representação, permitindo ao sujeito apreendê-los individualmente e em suas relações. O resultado dessa organização é chamado de núcleo ou esquema figurativo, uma construção estilizada do objeto que, absorvendo o excesso de significações, sintetiza, concretiza e coordena os elementos da representação, os quais, partilhados e confirmados por meio da 
conversação, se tornam "seres da natureza". A generalidade dessa "naturalização", sua importância em contextos sociais reais, tem sido amplamente demonstrada. A estabilidade do núcleo figurativo, bem como sua materialidade, lhe conferem o estatuto de referente e de instrumento para orientar percepções e julgamentos sobre a realidade (Jodelet, 1989). Tal fato tem importantes implicações para a intervenção social: qualquer ação que pretenda modificar uma representação só terá êxito se for dirigida prioritariamente ao núcleo figurativo, uma vez que este além de ser a parte mais sólida e estável da representação, também dele depende o significado desta (Abric, 1994; Ibáñez, 1988).

O segundo processo descrito por Moscovici é a ancoragem, que diz respeito ao enraizamento social da representação, à integração cognitiva do objeto representado no sistema de pensamento preexistente e às transformações que, em conseqüência, ocorrem num e noutro. Não se trata mais, como na objetivação, da construção formal de um conhecimento, mas de sua inserção orgânica em um repertório de crenças já constituído. Para Moscovici ( 1984), ancorar é classificar e rotular, e utilizamos esses processos para podermos nos familiarizar com algo que nos é estranho e, conseqüentemente, ameaçador. Ao classificar, escolhemos um dos protótipos estocados em nossa memória e com ele comparamos o objeto a ser representado, decidindo se ele se encaixa ou não na classe em questão, com base na coincidência entre uns poucos (ou mesmo um único) aspectos do protótipo. Aos protótipos que orientam as classificações correspondem expectativas e coerções, que definem os comportamentos adotados em relação às pessoas que eles classificam e aqueles que lhes sao exigidos. A interação com eles se desenrola de maneira a confirmar as características que lhes são atribuídas. Vale assinalar que, enquanto na objetivação a intervenção dos processos sociais se dá no agenciamento e na forma dos conhecimentos relativos ao objeto da representação, na ancoragem essa intervenção se traduz na significação e na utilidade que the são conferidos (Jodelet, 1990).

Assim, a interação dialética entre ancoragem e objetivação permite compreender: a) como a significação é conferida ao objeto representado; b) como a representação é utilizada enquanto sistema de interpretação do mundo social e de instrumentalização da conduta; e e) como se dá sua integração em

R. bras. Est. pedag., Brasilia, v.77, n.!87, p.497-524, set./dez. 1996 
um sistema de recepção, influenciando e sendo influenciada pelos elementos que aí se encontram (Jodelet, 1990).

\section{Metodologia utilizada}

Dez iniciativas voltadas para a ressocialização de crianças e adolescentes de ma foram incluídas no estudo. Destas, seis são organizações não-governamentais laicas, três são ligadas a organizações religiosas e uma pertence ao Estado.

Foram entrevistados 30 educadores sociais, selecionados de forma acidental entre aqueles que estavam disponíveis no momento da visita dos entrevistadores, sendo que, na maioria dos casos, eles haviam sido previamente indicados pela instituição a que pertencem. Sete dos entrevistados eram coordenadores de projetos e nenhum tinha menos de um ano na atividade. As entrevistas foram realizadas nos próprios locais de trabalho dos sujeitos (na instituição ou na rua), e os responsáveis pela coleta dos dados foram treinados por esta autora.

Quanto à caracterização dos educadores, 16 são do sexo feminino e 14 do sexo masculino, e suas idades variam entre 23 e 43 anos. Apenas um educador declarou ter formação específica para lidar com a clientela com que trabalha (um curso para alfabetização de meninos de rua). No que se refere à formação geral, 17 têm curso superior completo, embora nem sempre relacionado à atividade desempenhada (sete em Pedagogia, três em Educação Física, um em Psicologia, um em Serviço Social, um em Sociologia, um em Direito, um em Letras, um em Arquitetura e um em Engenharia) e um está cursando Fonoaudiologia. Dois têm mestrado completo (um deles fazendo o doutorado) e cinco o estavam cursando na época da coleta de dados. A formação dos demais não ultrapassa o segundo grau, sendo em alguns casos acrescida de cursos livres (tais como teatro, expressão corporal e outros).

Entre as razões apresentadas para a escolha da atividade, destaca-se a relação com trabalho anterior, geralmente relacionado a comunidades carentes $(\mathrm{N}=15)$. Outros mencionam a "sensibilidade ao problema" $(\mathrm{N}=4)$ ou "motivos 
ideológicos" ( $\mathrm{N}=2)$, havendo também aqueles que a justificam por representar uma "oportunidade de emprego" ou de "melhor salário" $(\mathrm{N}=4)$ ou que apenas declaram ter sido convidados $(\mathrm{N}=5)$.

As entrevistas foram semi-estruturadas, deixando que o entrevistado se expressasse livremente sobre os assuntos focalizados. Foi elaborado um roteiro para orientar os entrevistadores sobre os focos de interesse da pesquisa, embora a ordem das perguntas pudesse ser alterada em função do fluxo da conversa.

$\mathrm{O}$ roteiro era composto de quatro partes. A primeira visava à obtenção de informações que permitissem a caracterização dos educadores, acima apresentada. Na segunda parte indagamos a que atribuíam a existência de meninos de rua, que soluções viam para o problema e qual o papel do educador social. A investigação dos fatores responsáveis pela existência de "meninos de rua", bem como das soluções apontadas pelos educadores para a superação do problema, justifica-se pelo fato de que toda representação supõe uma "teoria" e, como tal, implica atribuições causais (Jodelet, 1989). O papel atribuído ao educador social pelos entrevistados indica como estes se posicionam, enquanto atores sociais, diante do objeto representado, permitindo fazer inferências sobre as relações entre representações e práticas. Na terceira parte, indagamos inicialmente aos entrevistados o que mais lhes chamava a atenção nos meninos e meninas de rua; em seguida, solicitamos que os caracterizassem de modo mais completo e, por fim, que nos falassem sobre alguns aspectos mais específicos - tais como principais formas de sustento, nível de escolaridade, faixa etária, proporção de meninos e meninas, e composição da renda familiar -, investigando, ainda, quais as fontes de seu conhecimento sobre a questão. Finalmente, na quarta parte, solicitamos, utilizando a técnica de associação livre, que dissessem como imaginavam que os meninos e meninas representavam alguns objetos relevantes para o processo de ressocialização, a saber: família, rua, escola, trabalho, auto-imagem e futuro.

As opiniões, crenças, informações, imagens e atitudes contidas no discurso dos educadores referente aos meninos de rua foram submetidos à análise de conteúdo (Bardin, 1977), procurando-se, inicialmente, descrever o conteúdo do campo de representação. Mediante a freqüência dos temas e a importância e 
o sentido a eles atribuídos pelos respondentes, buscamos depreender os elementos constitutivos da representação, bem como as relações entre eles, tentando chegar ao núcleo figurativo. Moliner (1994) aponta quatro características básicas que nos permitem identificar as cognições centrais (aqui representadas pelos núcleos figurativos): valor simbólico, poder associativo, saliência e conexidade. A primeira refere-se ao fato de que estas mantêm com o objeto uma relação necessária, "não negociável". Isto quer dizer que, na visão do grupo considerado, elas não podem ser dissociadas do objeto da representação, sob pena de este perder toda a significação. Poder associativo diz respeito à polissemia das noções centrais e à sua capacidade de associarse aos outros elementos da representação, uma vez que elas condensam o conjunto de significações. A saliência está diretamente relacionada às duas características anteriores: graças ao seu poder simbólico e à sua polissemia, as cognições centrais ocupam um lugar privilegiado no discurso, sendo evocadas mais freqüentemente que as demais. Finalmente, a conexidade é decorrente do poder associativo: em função dessa capacidade, as cognições centrais são aquelas que apresentam maior número de relações com os demais elementos da representação. Tais características, evidenciadas em vários estudos experimentais, serviram de critérios para a identificação do núcleo figurativo da representação de "menino de rua".

Para dar conta da estrutura identificada, porém, é necessário reconstituir os processos de formação da representação, ou seja, a objetivação e a ancoragem. No que se refere à objetivação, procuramos, partindo das distorções, desfalques e suplementações observadas na formação do núcleo figurativo, formular algumas hipóteses sobre as atitudes, os valores, as necessidades e os interesses subjacentes a esse processo, decorrentes da inserção sociocultural e profissional dos sujeitos e das interações mantidas com os meninos e meninas de rua, em decorrência de sua prática profissional. Quanto à ancoragem, buscamos identificar a que protótipos a representação dos meninos de rua estaria associada, bem como que tipo de práticas essa representação orienta e/ou justifica.

com o objetivo de avaliar o nível de rigor do estudo, utilizamos a técnica de "auditoria", proposta por Lincoln e Guba (1985). De acordo com esta técnica, um segundo pesquisador, com experiência na área, examinou tanto o processo, 
isto é, os procedimentos de coleta e análise dos dados, como o produto: transcrições das entrevistas, categorização, interpretações efetuadas e relatório final.

\section{Resultados e discussão}

As causas e soluções para o problema dos "meninos de rua", apontadas pelos educadores, bem como o papel do educador social, são apresentados abaixo. A seguir, focalizamos suas representações sobre os "meninos de rua" e, finalmente, formulamos algumas hipóteses sobre os processos cognitivos que deram origem a essas representações, a saber, a objetivação e a ancoragem.

\section{CAUSAS E SOLUÇÕES}

O modelo socioeconômico vigente no País é o principal fator responsável pela existência dos "meninos de rua", segundo a opinião unânime dos educadores sociais: o "sistema capitalista", a "estrutura socioeconômica", a "má distribuição de renda", a "miséria e o desemprego crescentes", o "êxodo rural", o "crescimento da economia informal" e a "ausência de políticas públicas que garantam à população carente os serviços básicos, como educação, saúde e programas habitacionais" são os principais aspectos apontados. A desestruturação familiar, a falta de afeto e a violência encontrada em muitas dessas famílias seriam decorrentes das causas econômicas apontadas. Sobre essas questões, assim se expressa um educador:

\footnotetext{
- O problema é estrutural. O Brasil cresceu tanto que chegou a ter o sétimo PIB do mundo. Só que isto foi feito com um motor chamado miséria, a miséria cresceu muito mais que o país. Nós somos uma construção que parou no meio, só ficaram os escombros... e não há recursos para terminar esse prédio, que ameaça ruir. (...) $\mathrm{O}$ desemprego cresceu assustadoramente, a economia informal impera, c o orçamento das famílias pobres dos grandes centros aperta-se cada vez mais, culminando com a necessidade de os filhos irem trabalhar muito cedo, num
}

R. bras. Est. pedag., Brasília, v.77, n. 187, p.497-524, set./dez. 1996 
mercado de trabalho que tem medo da legislação trabalhista e não quer empregálos... Daí, os meninos não têm escolha: partem para os sinais, a fím de vender submercadorias que não são de grande necessidade para ninguém. Ao voltarem para suas casas, são freqüentemente agredidos diante do pouco dinheiro obtido os pais descontam suas angústias neles, né? Até que um dia passam a temer mais suas casas do que a rua, onde acabam ficando.

Alguns lembram, ainda, a origem histórica do problema, remontando-a "à má solução da escravidão no País, que resultou na nãoinserção econômica das classes populares".

As soluções apontadas são coerentes com as causas atribuídas. A ênfase recai sobre as soluções estruturais, de longo prazo e de natureza preventiva, representadas por mudanças profundas no modelo econômico, que garantam emprego com salário digno para os pais e educação para os filhos. As falas que se seguem ilustram essas posições:

- Esse modelo econômico que está aí só faz reproduzir o status quo... Eu só vejo solução quando os pais tiverem condição de sustentar suas famílias, quando tiver emprego para todo mundo, quando a escola for um meio de ascensão, não só social, mas como ser humano... Tem de haver oportunidade igual para todo mundo.

- Enquanto o governo não implementar políticas públicas de apoio às famílias carentes, esse quadro não vai mudar. As soluções vão ser sempre paliativas.

- E preciso uma maior assistência às comunidades carentes, além de maiores oportunidades de trabalho e lazer, mantendo o menino integrado à comunidade... uma escola que funcione... $\mathrm{O}$ governo tem que assumir seu papel, com pessoas sérias tratando do assunto e evitando que essa responsabilidade seja passada a terceiros.

É importante assinalar que apenas cinco educadores se referiram a soluções de curto prazo, como programas de apoio e profissionalização, para atender os meninos que já estão na rua:

- A solução a longo ou médio prazo é reverter esse processo, mudar o sistema econômico, político e social. Ao mesmo tempo, é obrigação da sociedade buscar soluções imediatas para atender essas crianças, que precisam de soluções imediatas. 
Curiosamente, dois educadores consideram que não há solução: sempre houve e sempre haverá "meninos de rua".

\section{O papel do educador social}

Se há um consenso quanto às causas e soluções do problema, o mesmo não se pode dizer quanto à visão dos educadores sociais sobre o papel que lhes cabe: as respostas são extremamente variadas e, muitas delas, bastante vagas.

É certo, porém, que é possível identificar um pequeno grupo que parece ter uma visão mais clara do que propõe fazer em sua esfera de ação. Os indivíduos deste grupo afirmam que o educador social deve ter por objetivo levar os meninos à conquista da cidadania e que, para isso, deve funcionar como um mediador entre eles e a sociedade da qual foram excluídos. Consideram que, na medida em que os "meninos de rua" são produto de uma estrutura social perversa, não se pode restringir a atuação a eles, como se eles fossem "o problema", sendo necessário atuar também junto à sociedade, "denunciando as injustiças", "lutando pelos direitos deles", "dando-lhes voz". Nesse sentido, assim se expressa um educador:

- [O educador social] tem que encontrar medidas socioeducativas que ajudem essas crianças a reencontrar o contexto social. Para mim, o nosso papel é mediar relações, c uma trincheira política. A autonomia que esses meninos tem c um instrumento importante para que se possa ajudá-los a resgatar sua cidadania e a se defender dos males de uma sociedade opressora, que tem planos de morte para eles... E claro que, pela vida que levam, esses meninos passam a incorporar determinados comportamentos de vantagens, que são muito perigosas para sua vida pessoal e que colocam também em risco a vida coletiva, e nisso a intervenção diária do educador deve ser muito insistente... Mas, por mais doentes ou explorados que estejam, há como tranformá-los em pessoas dignas. Nosso papel é fazer com que eles compreendam suas vidas e possam resolvê-las sozinhos, sem a ajuda ou a dependência das ONGs. Mas, fundamentalmente, é a sociedade que precisa receber uma intervenção... O problema não é o produto, é o fabricante... Essa sociedade está apodrecida em suas bases... Individualista, mercantilista, produzindo esses meninos... uma vez, uma senhora me perguntou: "Quantos meninos desses você já recuperou?" Aí eu disse: "Olhe, minha senhora, muitos. Mas, pessoas como a senhora, nenhuma... Essa e a minha grande tristeza..." 
Esta fala sugere que a tarefa dos educadores inclui tanto aspectos políticos quanto educacionais. A maioria dos educadores, porém, tende a privilegiar ora os aspectos políticos - "conscientização dos meninos", "defesa de seus direitos", "pressão política" - ora os aspectos psicológicos - "dar atenção e carinho", "passar valores", "resgatar a auto-estima", "discutir com eles seus projetos de vida", "vencer as resistências deles, sem fórmulas".

Há, ainda, os que declaram "fazer tudo o que é possível", "ser pai, mãe, amigo, orientador", "ouvir seus desejos e procurar viabilizá-los", "atender às necessidades que precisam de soluções imediatas". Tal atitude, se às vezes denota uma certa desorientação, parece também representar uma tentativa de suprir as enormes carências decorrentes da situação de abandono a que esses meninos foram relegados. A esse respeito, diz uma educadora:

- O papel do educador c olhar por esse menino, é dar atenção a esse menino que ninguém atende, tentando ajudá-lo $\mathrm{cm}$ suas dificuldades, tentando atender às necessidades que ele traz.

A palavra "ponte" com o sentido de mediação, seja entre os meninos e outras alternativas de vida, ou entre eles e a sociedade, o governo ou outras instituições, aparece com alguma freqüência no discurso dos educadores ao se referirem ao seu papel. Observa-se, porém, que a forma de exercer essa mediação é vista de forma diferente por diferentes educadores e parece não estar clara para muitos deles.

Cabe assinalar que apenas três educadores consideram que seu papel é tirar os meninos da rua:

- Eu acho que o principal papel do educador social é fazer com que o menino perceba que a rua não c lugar pra se viver, não é o paraíso que ele imaginou quando saiu de casa... Fazer ele perceber que ali e tudo uma falsa liberdade... Sc $\mathrm{cm}$ casa ele é explorado pelos pais, na rua ele é explorado pelos maiores, pelo traficante, a menina é explorada pelo gigolô... E preciso encontrar um lugar para essas crianças...

- E possível fazer alguma coisa... Ajudar esses meninos a verem seu potencial cultural e de trabalho... O educador tem o dever de instigá-los a voltar à escola, apesar deles não gostarem, pois esta é a única chance que eles têm de competir no mercado de trabalho... 
Finalmente, observamos que, em alguns dos projetos e instituições incluídos no estudo, há uma certa homogeneidade entre os discursos dos educadores, o que parece refletir uma preocupação por parte dessas organizações em lhes oferecer orientação ou lhes propiciar algum tipo de reflexão sobre o problema. A maioria delas, porém, parece não estar conseguindo de seus educadores a clareza necessária sobre seu papel em um projeto de ressocialização desses meninos, objetivo declarado por essas instituições. Evidência disto é não apenas a grande disparidade entre as respostas, mas principalmente o fato de que estas, em sua maioria, se referem a atitudes ou ações de caráter emergencial, sem que nelas se possa identificar a existência de um projeto a longo prazo, uma preocupação com a reintegração dessas crianças à escola e à família (ou quem a substitua) e/ou com a preparação para o trabalho.

Tais resultados, se de um lado parecem indicar que muitos educadores se encontram meio perdidos em face da dificuldade da tarefa, de outro, podem ser decorrentes de uma esquematização da visão anteriormente mencionada, referente às causas e soluções do problema: se o modelo socioeconòmico vigente no País é o responsável pela existência de "meninos de rua", e se a solução do problema depende da substituição desse modelo, pouco restaria aos educadores fazer senão "administrar" o dia-a-dia dessas crianças e esperar ou lutar para que essas mudanças ocorram. Em outras palavras, é possível que uma visão esquemática da questão esteja levando esses educadores a verem sua atuação como um paliativo, restringindo-se a ajudar os meninos a sobreviverem nas ruas e a minorar seus sofrimentos, enquanto não surgem melhores alternativas de vida para eles.

\section{CARACTERIZAÇÃO DOS MENINOS DE RUA}

Ao serem perguntados sobre o que mais lhes chamava a atenção nos "meninos de rua", os educadores apresentaram respostas bastante variadas, predominando porém entre estas a resistência e a coragem (oito educadores), seguidas da autonomia e capacidade de organização social (cinco), do carinho

R. bras. Est. pedag., Brasília, v.77, n. 187, p.497-524, set./dez. 1996 
(quatro), da carência (três), e da consciência da exclusão a que foram submetidos (dois). A esperteza, a criatividade, a personalidade marcante, as mudanças de temperamento e também o abandono, o trauma familiar e a baixa auto-estima foram as outras características apontadas (com uma resposta cada), sendo que um dos educadores declarou que nada em especial lhe chamava a atenção.

À solicitação de uma caracterização mais ampla dos "meninos de rua", uns ativeram-se à gênese do problema, outros focalizaram a atitude das pessoas diante deles, embora a maioria tenha se centrado nas características dos próprios meninos. Os primeiros destacam a situação de miséria de suas famílias e a desestruturação familiar dela decorrente. Os que focalizam a atitude da sociedade ressaltam a indiferença e, principalmente, a discriminação social em relação a eles. Os que se centraram nas características diretamente relacionadas aos meninos - aí entendidas como atributos e comportamentos - os descrevem de uma maneira geral como crianças "que disseram não à miséria que tinham em casa e à escola, que não dá conta de suas necessidades", "com os mesmos problemas e pretensões das demais, apenas com manifestações diferentes em função das condições de rejeição e violência a que são submetidos", com "uma incrível capacidade de sobrevivência", "guerreiros que lançam mão de qualquer coisa para exercer seu direito à existência"; "adolescentes que já passaram pela escola, que perderam os vínculos familiares"; pessoas "com dificuldades de aceitar disciplina e hierarquia"; "carentes e ao mesmo tempo carinhosos"; que "usam a arrogância e a agressividade como defesa".

Algumas caracterizações, por se valerem da linguagem metafórica/ imagética merecem consideração especial pela maior riqueza simbólica que contêm:

"São como aves... são flutuantes", declarou um dos educadores, referindo-se à liberdade e à relação que os meninos têm com o espaço da rua, sua capacidade de driblar os carros e quem quer que os esteja perseguindo.

"Penso naqueles cobertores que eles usam, faça frio ou calor, como se fossem mantos de reis", o que sugere a transformação idealizada de um símbolo de pobreza (cobertores baratos, sujos e rasgados) em emblema de poder. 
"Eu os vejo vivendo em dois mundos: o mundo deles, com suas próprias leis e costumes, e o da sociedade, ao qual têm dificuldade de se adaptar". Curiosa a menção a esses "dois mundos". Lembram-nos os estudos de Chombart de Lauwe sobre a representação da infância nas sociedades contemporâneas, nos quais a autora afirma que esta representação pressupõe a existência de dois mundos distintos, o do adulto e o da criança, este último idealizado, projeção dos desejos sociais e associado à pureza, à espontaneidade, à justiça (Chombart de Lauwe, Feuerhahn, 1989).

- São como gatos de telhado, ora corajosos, ora medrosos, ora afetuosos, ora agressivos.

-Atores canastrões, que não conseguem comunicar adequadamente sentimentos c desejos, que expressam carinho de forma agressiva.

As duas últimas imagens simbolizam ambigüidades freqüentemente mencionadas pelos educadores, com relação ao comportamento dos meninos.

Finalmente, "um coraçãozinho sujo" remete à carência e ao carinho que os educadores vêem nos "meninos de rua" e, ao mesmo tempo, à sujeira, condição em que vivem, ocultando aos olhos das demais pessoas estas características. O uso do diminutivo parece ser uma tentativa de ancorar a imagem dos "meninos de rua" à representação idealizada da infância, acima mencionada, numa tentativa de carrear para eles atitudes vinculadas a essa representação, na qual, no que se refere ao imaginário social, eles certamente não se encaixam.

Após investigar como os educadores sociais representavam os "meninos de rua", deixando-os falar livremente sobre o tema, solicitamos que nos dissessem como imaginavam que os próprios meninos representavam alguns objetos por nós considerados relevantes para o processo de ressocialização, a saber: família rua escola trabalho, auto-imagem e futuro. Essas respostas são analisadas a seguir.

Família - "uma lembrança longínqua e dolorosa". A definição, dada por um dos respondentes, sintetiza com precisão a imagem que, segundo a opinião quase unânime dos educadores sociais, os "meninos de ma" têm de suas famílias. 
Longínqua, no sentido de que "não há mais vínculo" com ela ou de que ela "não é mais referência"; dolorosa, por estar associada ao "fracasso", à "mágoa", à "incompreensão", à "violência", à "omissão" (palavras ou expressões associadas à "família", por outros educadores). Neste quadro familiar, a figura do pai ou está ausente ou aparece como violento e autoritário. Quanto à mãe, já não há tanta clareza entre os educadores quanto à feição que assume, levando suas respostas a variar de "endeusada" a "bruxa", de "mosca morta" a "heroína". Pode-se identificar, entretanto, uma tendência a achar que ela ocupa, no contexto familiar, a posição mais favorável, uma vez que alguns educadores consideram que ela é vista ainda como uma referência e "respeitada, apesar de tudo".

Rua - A maioria dos educadores sociais acredita que a visão positiva da rua predomina amplamente entre os meninos e meninas, que a vêem como liberdade e sobrevivência. Transparece mesmo, na fala de alguns educadores, uma visão romântica da rua, evidenciada por expressões como "fascinante", "um oásis", "um grande barato", "o paraíso"(esta usada por dois educadores). Apenas cinco educadores consideram os meninos ambivalentes com relação à rua, na medida em que a associam à liberdade e à sobrevivência, mas também à violência e à morte. Finalmente, seis educadores dizem simplesmente que os meninos vêem a rua como "a casa deles". Quanto à turma da rua, a maioria dos entrevistados afirma que esta é vista como família e, como tal, assume funções a ela associadas no imaginário social, tais como aconchego, segurança e proteção.

Escola - Enquanto alguns consideram que os "meninos de rua" vêem a escola como "uma necessidade", "um sonho", "uma conquista impossível", a maioria afirma que eles simplesmente a rejeitam, acham-na "um tédio", "uma prisão", ou que "não serve pra nada". uma posição intermediária pode ser vista entre os que sugerem que eles rejeitam a escola que existe, que não atende às suas necessidades. $O$ que nos parece importante assinalar aqui é que, seja por ser rejeitante, seja por ser rejeitada, a quase totalidade 
dos educadores vê a reintegração à escola, pelo menos à escola regular, como algo totalmente fora do universo dos "meninos de rua".

Trabalho - A maioria dos educadores sociais considera que os "meninos de rua" têm uma visão negativa do trabalho, considerando-O "coisa de otário", que "não dá camisa a ninguém"; que só serve "pra arrumar algum" e "quando tiver vontade, sem esforço", "aturar ordem de patrão, acordar cedo, nem pensar". Alguns entrevistados, porém, acreditam que eles sabem ser uma necessidade, sua única saída, embora ressaltem prováveis dificuldades na adaptação dos meninos ao trabalho.

Auto-imagem - Para a maioria dos educadores sociais, a auto-imagem dos "meninos de rua" é bastante negativa: eles se acham "feios", "coisas", "bichos", "desrespeitados". Há, porém, os que consideram que eles se acham "espertos", "fortes" e "auto-suficientes". A interpretação para esta discrepância parece estar contida nas observações feitas por alguns educadores, segundo as quais a exibição de força e auto-suficiência é puramente defensiva. Outros, ainda, consideram que a auto-imagem dos meninos é "confusa" ou "mutável".

Futuro - A maioria dos educadores sociais diz que os "meninos de rua" vivem apenas o presente, o futuro não existe: para eles o que vale é o "aqui e agora", não fazem planos nem têm perspectivas. Alguns dos entrevistados interpretam essa atitude como uma defesa decorrente da consciência de que "a morte ronda o seu dia-a-dia".

A visão da maioria dos educadores, no que se refere ao conteúdo das representações dos "meninos de rua" sobre os objetos aqui focalizados, é bastante coerente com aquelas apresentadas pelos próprios meninos e meninas, e por nós investigadas em estudo anterior (Alves-Mazzotti, 1994). Apenas quanto à representação de rua, uma observação se faz necessária: 
enquanto a maioria dos educadores acredita que a rua é associada à liberdade, os próprios meninos a associam mais à violência do que à liberdade, sendo a visão destes com relação à rua melhor caracterizada como ambivalente. A análise dos processos de construção das representações pelos "meninos de rua" permitiu verificar que a imagem da rua como espaço da liberdade está fortemente ancorada à representação que eles têm do grupo de companheiros da rua. Estes são vistos pelos meninos como uma rede de proteção contra a violência tanto de marginais quanto da polícia, o que permite que se sintam livres. A rua enquanto espaço público, porém, é vista como perigosa e inóspita.

O nível de informação dos educadores sobre os "meninos e meninas de rua" foi avaliado, ainda, mediante respostas a perguntas sobre aspectos específicos relacionados aos meninos, tais como renda per capita familiar, composição da família, nível de escolaridade, faixa etária, proporção de meninos e meninas e principais formas de sustento. As respostas sobre estes aspectos específicos foram comparadas aos resultados de uma ampla revisão de pesquisas sobre "meninos de rua", realizada por Rizzini e Rizzini (1992).

Duas observações são aí dignas de nota, por evidenciarem distorções significantes, produzidas pelo processo de objetivação. A primeira refere-se à renda per capita familiar, a qual foi subestimada pela quase totalidade dos educadores: enquanto as pesquisas a situam em tomo de meio salário mínimo, as respostas variaram entre um (apenas um educador deu esta resposta) e um décimo de salário minino, sendo que a média foi de um quinto de salário. Tal distorção parece ter o objetivo de enfatizar a importância da pobreza extrema como o determinante da condição de "menino de rua", caracterizando-o, assim, como vítima da exclusão social. Se é certo que a pobreza é um fator importante na opção pela rua, também é verdade que crianças igualmente pobres permanecem junto a suas famílias (Alves, 1992). A segunda observação diz respeito à principal forma de sustento dos meninos e meninas: a maioria dos educadores enfatiza os "biscates" e a "mendicância", minimizando as atividades ilegais; quando se referem aos furtos, a menção a estes é invariavelmente antecedida pelo adjetivo "pequenos". 
No que se refere às fontes de informação utilizadas pelos educadores na construção de seu conhecimento sobre os "meninos de rua", predomina o contato direto e, em menor escala, a conversação (geralmente discussões, programadas ou informais, no âmbito das instituições). Outros se referem, ainda, a uma literatura de apoio (em Sociologia, em Educação Popular), mas a grande maioria parece não valorizá-la, uma vez que esta quase não é citada, havendo mesmo aqueles que fazem questão de ressaltar que "teorias não resolvem". Os educadores são unânimes em afirmar que os meios de comunicação de massa (jornais, revistas e televisão) focalizam apenas a violência, apresentando os meninos geralmente como produtores dessa violência, mas também como vítimas. Nas palavras de um educador, eles são apresentados "como assassinos ou assassinados".

A atitude que pode ser depreendida do conteúdo das representações efetuadas pelos educadores é, como seria de esperar, francamente positiva. O que talvez não seja tão óbvio, embora seja compreensível, é a parcialidade observada na avaliação do comportamento dos meninos pela maioria dos educadores, levando-os a justificar mesmo os comportamentos menos éticos, como o roubo e a agressão, pela exclusão e violência a que são submetidos. Um educador assim se expressa a respeito:

- Eles vivem de pequenos furtos...Viver na rua custa caro...,Paga-se caro para manter a integridade física, para ter um lugar para dormir. E o produto desses delitos que os mantém vivos, que permite pagar compromissos com terceiros, obrigações de contra-relações que existem nas ruas com policiais, camelôs, seguranças de estabelecimentos comerciais.

Em resumo, as imagens construídas pelos educadores apresentam os "meninos de rua" como, ao mesmo tempo, vítimas e heróis, minimizando o lado anti-social de seu comportamento. Tais distorções, desfalques e suplementações (Jodelet, 1989) são, como vimos, patte inerente ao processo de objetivação e refletem a atuação de valores e necessidades do grupo. A idealização que pode ser identificada nas imagens fornecidas pelos educadores parece ter uma função defensiva, facilitando a interação cotidiana com os meninos. 
Assim, considerando-se o conjunto das representações apresentadas pelos educadores, identificamos o seguinte núcleo figurativo resultante do processo de objetivação: os "meninos de rua " são vítimas dos processos de exclusão social que resistem. Munidos de coragem, organização social e autonomia, lutam para sobreviver ao compio social que se instalou contra eles, representado pelo modelo socioeconômico iníquo, que levou suas famílias à desagregação e à violência; pela escola, que os exclui, e pela sociedade, que os discrimina.

Resta-nos, finalmente, formular algumas hipóteses sobre o processo de ancoragem. Dissemos anteriormente que a ancoragem, dialeticamente ligada à objetivação, nos permite compreender as representações sociais como um sistema de interpretação que orienta a relação do sujeito com o mundo e com os outros, guiando suas condutas e comunicações, revelando, portanto, aspectos relevantes sobre o grupo que as elabora.

A comparação entre os conteúdos que entram na construção do núcleo figurativo e o papel que os educadores se atribuem parece indicar algumas relações entre representação social e conduta. Se o fato de ser vítima da exclusão social é o núcleo da representação de "meninos de rua", compreendese porque os educadores sociais tendem a enfatizar mais a defesa dos direitos do que a reorientação da conduta desses meninos e meninas, embora este seja um aspecto essencial à tarefa de ressocialização a que se propõem. Por outro lado, ver os meninos como alguém que, apesar de todas as vicissitudes, continua lutando contra os mecanismos que o excluem, leva os educadores a admirá-los, o que talvez explique o fato de que procuram minimizar ou mesmo justificar seus comportamentos anti-sociais.

Esse núcleo parece refletir a "leitura romântica" sobre a educação dos "meninos de rua", descrita por Ferreira (1993). Segundo essa visão, o comportamento desses meninos não oferece maiores riscos nem fere princípios de nossa sociedade. Assim, basta respeitá-los, comprendendo as especificidades de sua cultura, para que eles convivam pacificamente com outros grupos sociais. No que se refere à escola, bastaria que esta lhes abrisse suas portas, deixando que eles dela participassem se e quando quisessem, que o próprio convívio 
escolar se encarregaria de corrigir as seqüelas deixadas pela vida na rua, o que, segundo essa autora, não corresponde à realidade.

Um outro ponto merece ser destacado. Vimos anteriormente que, ao apontarem o modelo socioeconômico, responsável pela pobreza extrema de suas famílias, como o determinante da existência de "meninos de rua" e a reversão do referido modelo como a única solução capaz de oferecer aos meninos melhores alternativas de vida, os educadores parecem colocai um impasse à tarefa a que se propõem. Mas a análise das relações entre as representações por eles atribuídas aos meninos permite compreender melhor esse impasse. Referimo-nos especialmente às representações de família, escola, trabalho e rua.

As duas primeiras, que são em tese as principais instâncias de socialização, foram descartadas pelos meninos e, segundo a opinião dos educadores, as possibilidades de reversão dessa situação parecem ser ínfimas, uma vez que a volta ao convívio familiar e à escola não são mencionadas entre as soluções por eles apontadas para a questão dos meninos de rua, nem ao se referirem ao papel do educador social. Soluções relacionadas à família e à escola, quando mencionadas, referem-se à prevenção do problema e não a alternativas para as crianças que já estão na rua. Quanto ao trabalho, a grande maioria dos educadores afirma que os meninos o rejeitam, por não garantir o sustento. Mesmo que esta avaliação seja verdadeira, como indicam pesquisas feitas com os próprios meninos (Alves-Mazzotti, 1994), parece estranho que esse fato não mereça destaque nas falas dos educadores sobre seu papel. Por outro lado, vimos também que muitos educadores, ao se referirem à visão que os meninos têm da rua, tendem a supervalorizar os aspectos positivos, como "fascínio e liberdade", em detrimento dos negativos.

Sobre esses aspectos, vale reproduzir as conclusões de uma pesquisa recente, realizada por Campos e Fávero (1994), focalizando a representação dos educadores sociais sobre o modo de vida dos "meninos de rua". Essa pesquisa sugere que o discurso dos educadores, embora eivado de contradições, indica que estes parecem considerar que o modo de vida na rua é, em muitos aspectos, melhor do que o modo de vida que os meninos tinham na família e também do que o que lhes poderia ser assegurado pelo trabalho formal. Acrescentam os 
autores que os educadores fazem uma avaliação comparativa entre a atividade da rua e o trabalho formal, concluindo que a primeira é mais "vantajosa", tanto do ponto de vista dos ganhos como do esforço empreendido.

Os pontos de contato entre esses resultados e os obtidos em nosso estudo são claros. As contradições entre seu papel ressocializador e suas avaliações sobre o modo de vida dos meninos diante das alternativas que o modelo social vigente reserva às crianças nascidas nas famílias muito pobres levam os educadores sociais a uma ambivalência quanto à necessidade de "tirar os meninos da rua". Tal ambivalência, por sua vez, aliada à dificuldade real de levar os meninos à construção de um novo projeto de vida, parece estar gerando nesses educadores uma grande perplexidade quanto ao sentido de sua atuação. Daí, a vasta gama de respostas obtidas com relação a essa questão, variando da onipotência e da superproteção à impotência diante do peso das determinações sociais. E nem uma nem outra dessas atitudes parece eficaz para levar os "meninos de rua" à "elaboração de um novo projeto de vida" que permita sua reintegração na sociedade, principal finalidade da ação do educador social.

\section{Referências bibliográficas}

ABRIC, J.C. L'organization interne des représentations sociales: système central et système périphérique. In: GUIMELLI, C. (Ed.). Structures et transformations des représentations sociales. Lausanne: Delachaux et Niestlé, 1994.

ALVES, A.J. Meninos de rua e meninos na rua: estrutura e dinâmica familiar. In: FAUSTO, Ayrton, CERVINI, Ruben (Ed.). O trabalho e a rua: crianças e adolescentes no Brasil urbano dos anos 80. Sao Paulo: Cortez, 1992. 244p.

ALVES-MAZZOTTI, Alda Judith. Street kids in Brazil: comparing representations. Trabalho apresentado na Reunião Anual da American Educational Research Association (AERA), realizada em New Orleans, abril de 1994. 
ALVIM, M.R.B., VALLADARES, L. Infancia e sociedade no Brasil uma análise da literatura. Boletim Informativo e Bibliográfico de Ciências Sociais, Rio de Janeiro, n.26, p.3-37, 1988.

BARDIN, Laurence. L'analyse de contenu. Paris: Presses Universitaire; de France, 1977.

CAMPOS, P.H.F., FÁVERO, M.H. O trabalho da rua: as representações de trabalho em grupos de meninos de rua e educadores sociais de rua Trabalho apresentado na $2^{\text {a }}$ Conferência Internacional sobre Repre sentações Sociais, realizada no Rio de Janeiro, em 1994.

FERREIRA, Nilda Tevês. Meninos de rua - um desafio para a escola. En Aberto, Brasília, v.13, n.53, p.85-93, jul./set. 1993.

GUIMELLI, C. Présentation de l'ouvrage. In: (Ed.). Structure et transformations des représentations sociales. Neuchâtel: Delachau: et Niestlé, 1994.

IBANEZ, G.T. Representations sociales: teoria y método. In: Ideologia de la vida cotidiana. Barcelona: Sendai, 1988.

JODELET, Denise. Représentation sociales: un domaine en expansion. Ir (Ed.). Les représentations sociales. Paris: Presse Universitaires de France, 1989. 424p.

. Représentation sociales: phénomène, concept et théorie. Ir MOSCOVICI, Serge (Ed.). Psychologie sociale. 2.ed. Paris: Presse Universitaires de France, 1990.

R. bras. Est. pedag., Brasilia, v.77, n. 187, p.497-524, set/dez. 1996 
LAUWE, Marie Jose Chombart de, FEUERHAHN, N. La représentation sociale dans le domaine de l'enfance. In: JODELET, Denise (Ed.). Les représentations sociales. Paris: Presses Universitaires de France, 1989. $424 p$.

LINCOLN, Yvonna S., GUBA, Egon G. Naturalistic inquiry. Beverly Hills: Sage Publications, 1985. 416p.

MOLINER, P., GUIMELLI, C. (Ed.). Structures et transformations des représentations sociales. Neuchâtel: Delachaux et Niestlé, 1994.

MOSCOVICI, Serge. The phenomenon of social representations. In: FARR, Robert M., MOSCOVICI, Serge (Ed.). Social representations. Cambridge: Cambridge University Press, 1984.412p. (European studies in social psychology).

. A representação social da psicanálise. Tradução de Álvaro Cabral. Rio de Janeiro: Zahar, 1978.

PENNA FIRME, Thereza, TIJIBOY, Juan Antonio, STONE, Vathsala Iyengar. Avaliação do impacto de programas alternativos de atendimento aos meninos de rua. Brasilia: Unicef, 1987. 130p.

RIZZINI, I., RIZZINI, I. "Menores" institucionalizados e meninos de rua: os grandes temas de pesquisa na década de 80. In: FAUSTO, Ayrton, CERVINI, Ruben (Ed.). O trabalho e a rua: crianças e adolescentes no Brasil urbano dos anos 80. Sao Paulo: Cortez, 1992. 244p.

VALLADARES, L., IMPELIZIERI, F. Ação invisível: o atendimento a crianças carentes e a meninos de rua no Rio de Janeiro. Rio de Janeiro: Iuperj, 1991. 
Alda Judith Alves-Mazzotti é professora titular de Psicologia Educacional, no Laboratório de Imaginário Social e Educação da Faculdade de Educação da Universidade Federal do Rio de Janeiro (UFRJ).

The study investigated how Brazilian "social educators " who work for various programs aimed at supporting and resocializing "street children " in the municipality of Rio de Janeiro represent these children as well as their vision concerning the significant aspects of the universe of these children. Additionally, the attributions made by these educators, regarding the causes and possible solutions for the issue of "street children ", were investigated, as well as their views about their own professional role. Considering all the elements of the representations presented by the educators, the following figurative schema was identified: "street children are victims of social exclusion who cope ". With courage, autonomy and social organization skills, they manage to survive in spite of the social exclusion mechanisms represented by the perverse economic model that led their families to disaggregation and violence, by the school that excluded them and by society at large that discriminates them.

La présente recherche a étudié la representation de "l'enfant de la rue" présentée par les "éducateurs sociaux" brésiliens qui s'occupent de ces enfants. Nous avons voulu savoir aussi comment ces éducateurs expliquent l'existence des "enfants de la rue", quelles sont les solutions présentées et comme ils voient ses rôles dans le contexte actuel. Les résultats obtenus ont mis en évidence le suivant noyau figuratif: "les enfants de la rue " sont des victimes des processus d'exclusion sociale qui résistent. Avec courage, organisation et autonomie, ils luttent pour survivre au complot social installé contre eux, representé par le modèle économique pervers

R. bras. Est. pedag., Brasilia, v.77, n.187, p.497-524, set./dez.. 1996 
qui a mené sa famille à la désagrégation et à la violence, par l'école excluante, par la société discriminante.

Este estudio procuró investigar de que manera los "educadores sociales " vinculados a programas de atención a "niños y niñas de la calle " en el municipio de Rio de Janeiro representan a esta población. Se investigó también cómo tales educadores sitúan la cuestión de los "niños de la calle "; más específicamente, a qué atribuyen la existencia del problema, las soluciones posibles y el papel del educador social en el contexto actual. Considerándose el conjunto de las representaciones planteadas pelos educadores, se identificó el seguiente núcleo figurativo: los "niños de la calle" son víctimas de los procesos de exclusión social que resisten. com su coraje, capacidad de organización social e autonomía, luchan para sobrevivir al complot social instalado contra ellos, representado por el modelo socioeconómico que llevó sus familias a la disgregación y a la violencia, por la escuela que los excluyó y por la sociedad que los discrimina 